\title{
Daños en el recubrimiento de Betún-Látex de Placas-Artesa para cubiertas
}

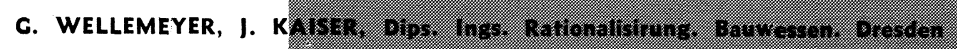

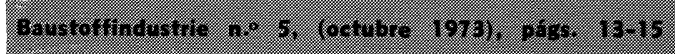

\section{MEDIDAS PARA LA PREVENCION DE DAÑOS}

A continuación se presenta un elemento de "artesa para cubierta", recubierto de betún látex por el procedimiento de componente único. En este caso se hace referencia sobre todo a daños en el recubrimiento, que se presentaron después de cierto tiempo y tuvieron su causa en la ejecución inadecuada.

Las explicaciones han de contribuir a evitar otros fracasos, $y$ en el caso de ulteriores trabajos, poder construir según el actual estado de los conocimientos.

\section{Construcción del elemento "artesa para cubiertas"}

Para la fácil construcción por elementos con volumen de varios pisos se necesitan, inmediatamente después del montaje, elementos o placas de cubierta adecuados a la función y que deben cumplir los siguientes requisitos:

- Elementos rápidamente montables, incluidas las juntas.

- Prefabricación, con el máximo acabado: cubierta del tejado, esclusa del tejado, tubos de revestimiento, salidas de aguas, etc.

- Ser intercambiables en grado elevado o reducidas variantes y posibilidad de unión de los elementos de la cubierta entre sí.

Los correspondientes trabajos de investigación han permitido construir un elemento de artesa para cubierta en hormigón armado con acabado previo muy completo, de formato grande (figs. 1 y 2). La base es el elemento artesa para cubierta logrado en la Universidad Técnica de Dresden, Sección de Ingeniería de la Construcción.

El elemento tiene unos bordes constantemente elevados, circundantes, de hormigón armado, en los que la placa está empotrada oblicuamente. El desnivel alcanza un 2,5 \%.

El grado de prefabricación elevado requiere una cubierta de tejado que pueda prepararse industrialmente. Por esta razón se ha previsto un recubrimiento de betún-látex por el procedimiento de inyección.

El agua de lluvia se desvía a través de dos salidas de agua con gárgolas que han de fijarse en la obra. Las juntas así como los bordes exteriores de las artesas se recubren con chapa de aluminio. 
Las piezas complementarias se montan antes de la colocación de la cubierta, para evitar trabajos posteriores en el tejado.

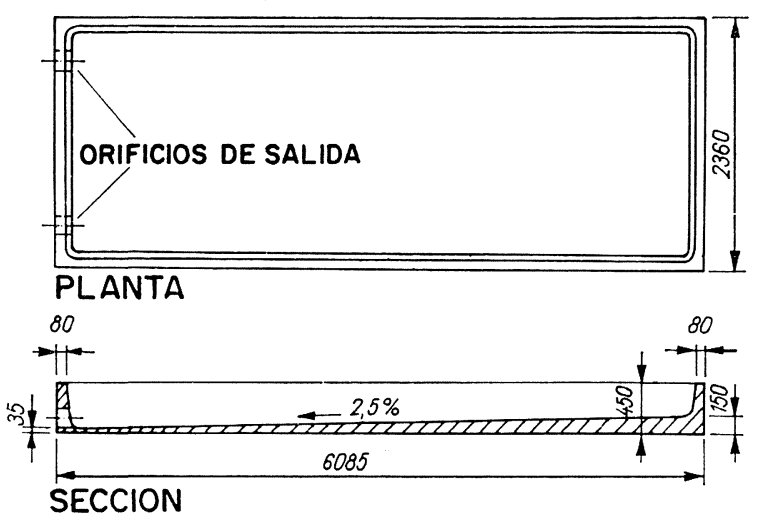

Fig. 1.-Placa de artesa para tejado de hormigón armado. (Esquema de construcción).

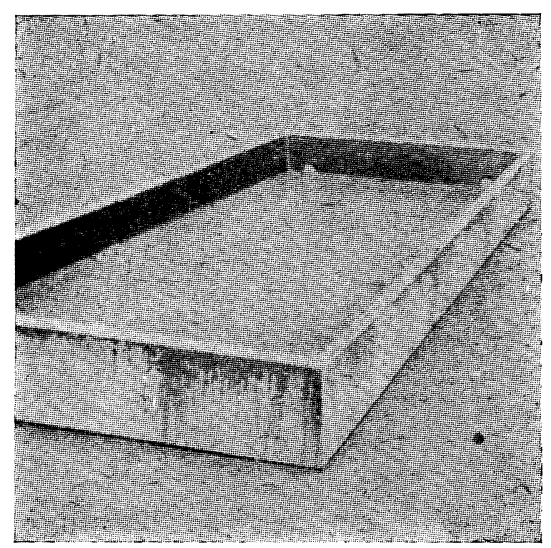

Fig. 2.-Placa artesa para tejado de hormigón armado.

\section{Fabricación y montaje}

Las artesas para cubierta se fabrican en posición de montaje con encofrado exterior y de cementación. El recubrimiento de betún-látex, por el procedimiento de componente doble según TGL 23725 , hoja 2 (cartón para tejado y recubrimiento de $5 \mathrm{~mm}$ ) no pudo realizarse en la central de hormigonado debido a su complicada tecnología. Mediante una autorización especial de la inspección estatal de la construcción de la Academia de Construcción de la República Democrática de Alemania se colocó un recubrimiento de betún-látex en 6 capas (procedimiento de componente único).

La contrucción de ensayo en Dresden [tren de estuco-hierro (construcción 9-Mp)]y las obras de construcción de elementos espaciales (tipo "Dresden 2") se recubrieron con los elementos descritos. Ensayos adicionales del ASMW Dresden confirmaron la estanqueidad al agua del recubrimiento, incluso en condiciones extremas. Se transportaron los elementos y se montaron con grúa giratoria móvil y traviesa reticulada.

\section{Resultados de la prueba}

La construcción de hormigón armado cumplió las Normas. No se originaron grietas o humedades en la parte inferior de las artesas.

Las piezas complementarias, como tubos de vapor, exclusa del tejado, salidas de agua, gárgolas y recubrimiento de juntas, cumplieron igualmente.

\section{Daños del recubrimiento}

En las inspecciones del tejado efectuadas en los meses de enero a marzo de 1972 se vieron, en un $70 \%$, aproximadamente, de las "artesas" montadas, daños en forma de grietas en las capas superiores de betún-látex (fig. 3). Estas trajeron como consecuencia daños superficiales debido a la humedad y al cambio de hielo y deshielo subsiguientes.

En verano la radiación solar produjo gran formación de burbujas (fig. 4). 
La formación de burbujas debida a la influencia del calor se explica por inclusiones de humedad entre cada una de las capas de betún-látex, es decir, a causa del insuficiente secado o a la rápida sucesión de aplicación de cada una de las capas. Las medidas dieron como resultado que el factor de resistencia de las capas bituminosas à lá difusión del vapor es aproximadamente 10 veces superior a lo que se había supuesto. Las grietas y los desprendimientos resultantes ahí son igualmente consecuencia de estàs inclusiones de humedad, de la humedad que ha penetrado en las burbujas reventadas, así como de los cambios de hielo-deshielo. Ambos fenómenos se basan en defectôs de ejecución, causados por falta de conocimientos teóricos y experiencias prácticas.

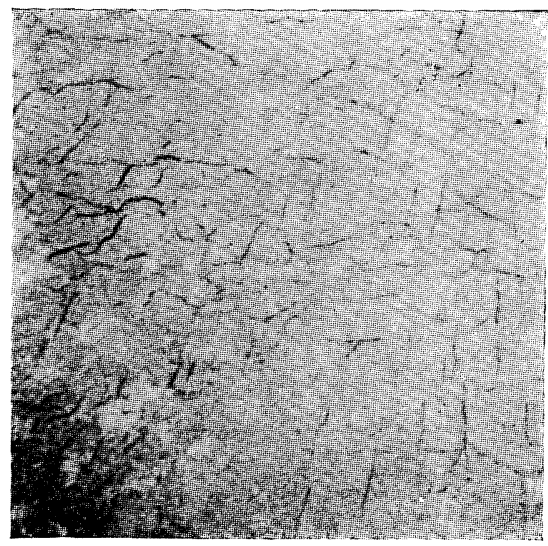

Fig. 3.-Crietas en las capas superiores de betún-látex.

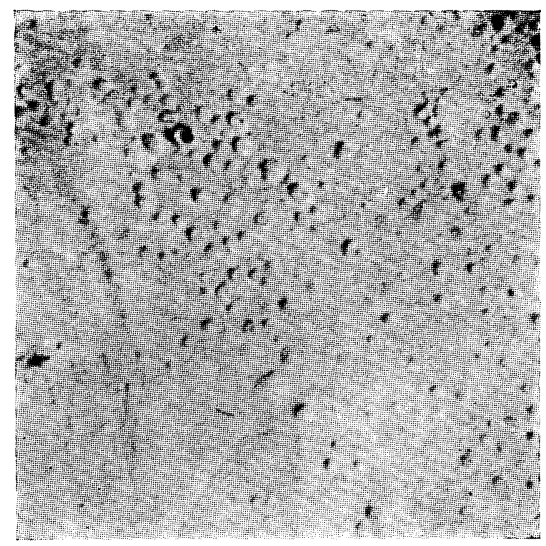

Fig. 4.-Formación de burbujas en el recubrimiento de betún-látex.

\section{Medidas para la prevención de daños}

El recubrimiento de las obras o construcciones con emulsión de betún-látex debe efectuarse sobre superficies cubiertas y a temperaturas superiores a $5^{\circ} \mathrm{C}$. Como la calidad del recubrimiento depende también de la velocidad del viento y de la humedad del aire, es más ventajoso que la superficie se proteja por todas partes.

Las capas deben aplicarse por pulverización.

La superfice del tejado debe ser plana y presentar el desnivel mínimo.

Las superficies de hormigón deben limpiarse cuidadosamente antes del recubrimiento.

Cumplir estas condiciones en la producción industrial, es elaborar un rágimen tecnológico exacto, científicamente basado y documentado por experiencias prácticas. Debe comprender las siguientes cuestiones:

1) Indicación del período mínimo entre la fabricación del elemento de hormigón y el comienzo de la impermeabilización, dependiendo de las diferentes duraciones del fraguado del hormigón.

2) Determinación del período mínimo de los ciclos de recubrimiento (período entre la colocación de cada una de las capas). 
3) Duración de la necesaria protección del recubrimiento contra el sol y precipitaciones (influencia de los rayos ultravioleta).

4) Selección de los materiales de recubrimiento.

5) Elección del equipo para el recubrimiento y del procedimiento de aplicación.

6) Determinaciones respecto del mantenimiento y protección del recubrimiento en trabajos posteriores (por ejemplo cierre de juntas).

El régimen técnico que se adopte debe cumplir las condiciones anteriores para que así el fabricante de la cubierta del tejado asuma la garantía. Al mismo tiempo la empresa que fabrica material de recubrimiento debe asumir la garantía del mismo elaborado según la tecnología adoptada.

\section{B I B L I O G R A F I A}

(1) Ritter, J, Düsing, P.: Vorgefertigte, vollkompletirte Montage-Flachdachelement. Bauzeitung 27 (1973) n. ${ }^{\circ}$, pág. 88 y sgtes. 